\title{
The Behavior of Olive Stone Powder at High Temperature Steel Corrosion
}

\author{
Rami A. Qassim, Sahib M. Mahdi, and Jafar G. Majeed
}

\begin{abstract}
Corrosion of metals is the most significant and difficult life problems, especially its produce an economical losses, therefore, many researches carried out in various fields in order to reduce the bad effect of corrosion, particularly in acidic environments. Using corrosion inhibitors is one of the methods of prevention corrosion, which come up on organic and inorganic materials, in this study, dried Olive stone powder used as corrosion inhibitor in solutions of hydrochloric acid with concentrations of $0.5,1$ and 1.5 molarity at $40{ }^{\circ} \mathrm{C}$ and $55{ }^{\circ} \mathrm{C}$, where $10 \mathrm{gm}$ per litter of acid. The corrosion rates of mild steel samples were measured using potentiostat device with reference of calomel electrode. The result shows that corrosion rate reduced by adding the Olive stone powder. The highest inhibition efficiency percent for acid solutions with concentration of 1.5 molarity is $93.8 \%$ at $55^{\circ} \mathrm{C}$, while the lowest was $49.6 \%$ in the 0.5 molarity solution at $55^{\circ} \mathrm{C}$. The chemical composition of the Olive stone powder is shown to be an organic matter of a high carbon and hydrogen content making a carbonyl compound which has the greatest effect in inhibition corrosion in acidic solutions such as hydrochloric acid.
\end{abstract}

Index Terms-Olive Stone Powder; HCl Acid Medium; Mild Steel; Inhibitor; Potentiostat.

\section{INTRODUCTION}

Several different techniques can be employed to slow or prevent corrosion of a metallic structure such as corrosion inhibition by organic inhibitors, an inhibitor is a chemical substance or mixture of substances which when added in very low concentrations in a corrosive environment efficiently prevents or slows corrosion without any reaction with the system components of the environment [1]-[6]. These inhibitors can be organic or inorganic combinations and they are dissolved in aqueous environments. [7]. So the practical criteria for selection of the corrosion inhibitors from the variety compounds of inorganic and organic substances with sufficient inhibiting properties are not only their inhibition efficiency but it must be the safety of use, compatibility with other chemicals in the structure, economic constraints and environmental concerns [8]. There are several authors showed a lot of studies to find good effective inhibitors for mild steel in different mediums [9][11].

Published on February 23, 2018

R. A. Qassim, Master student in Materials Engineering Department, College of Engineering, Mustansiriyah University, Baghdad, Iraq. (E-mail: rami.alqaysi@yahoo.com).

S. M. Mahdi, Assit. Prof. in Materials Engineering Department, College of Engineering, Mustansiriyah University, Baghdad, Iraq. (E-mail: sahebmahdi@yahoo.com).

Dr. J. G. Majeed, Assit. Prof. in Materials Engineering Department, College of Engineering, Mustansiriyah University, Baghdad, Iraq. (E-mail: drjafar2005@yahoo.com).
The purpose of inhibitors is to form a barrier of one or several molecular films against the attack of acid. This protective action associated with chemical and/or physical adsorption containing a variant charge of the adsorbed substance and transfer the charge from one phase to another, Because of the toxic nature and high cost of some chemicals currently are used as inhibitors, like nitrites and chromates, it is also important to develop friendly environmental and inexpensive inhibitor [12].

The Olive stone can be used as a green corrosion inhibitor which structurally be separated from the olive fruit, the Olive can be divided to three part: (1) the skin, (1.0-3.0\% weight), which contains the carotenoids, chlorophyll, and anthocyanins that account for the color; (2) the pulp or flesh, (70-80\% of the fruit), (3) and the stone, called the woody endocarp contain (18-22\% of the Olive weight), which can be dried and then crushed to become a powder.

The whole stone consists of the wood shell (stone) and the seed. The stone is gained by filtration of byproducts from the Olive oil extraction. Cellulose, hemicellulose and lignin are the main components of this lignocellulosic biomass, although fat and protein are present in such quantities [13].

The most hazardous effects of the synthetic organic inhibitors and the hurting the environmental systems have now made some researchers to focus on the need to develop cheap, non-toxic, sustainable and environmentally types of natural products as corrosion inhibitors [14].

\section{GENERAL}

The electrochemical Tafel test method, chemical composition analysis test and FT-IR (Fourier Transform Infrared spectroscopy) test were used in order to observe the Olive stone powder effects on mild steel samples corroded in three different concentrations of $0.5,1$ and 1.5 Molarity of $\mathrm{HCl}$ mediums at $40^{\circ} \mathrm{C}$ and $55^{\circ} \mathrm{C}$.

Powder of diameter 150 micron of dry Olive stone are added to three different concentrations of $0.5,1,1.5 \mathrm{M} \mathrm{HCl}$ mediums at $40^{\circ} \mathrm{C}$ and $55^{\circ} \mathrm{C}$.

\section{EXPERIMENTAL}

\section{A. The Chemical Composition specimen test}

The chemical composition of the Mild steel samples is list in Table I. Cylindrical samples of $4.8 \mathrm{~cm}^{2}$ surface area are used for electrochemical tests.

TABLE I: THE CHEMICAL COMPOSITIONS OF MILD STEEL SPECIMENS.

\begin{tabular}{llllllll}
\hline \hline $\mathrm{Mn} \%$ & $\mathrm{~S} \%$ & $\mathrm{P} \%$ & $\mathrm{Mo} \%$ & $\mathrm{C} \%$ & $\mathrm{Si} \%$ & $\mathrm{Cr} \%$ & $\mathrm{Fe} \%$ \\
\hline 1.33 & 0.01 & 0.02 & 0.003 & 0.15 & 0.03 & 0.01 & Rem. \\
\hline \hline
\end{tabular}




\section{B. FT-IR Test}

FTIR - Fourier Transform Infrared - spectroscopy analysis and testing identifies chemical compounds in a wide range of capacities also can identifies chemical bonds in a molecule by producing an infrared absorption spectrum in the Olive stone powder that shows the important compounds and bonds which eliminates the acidity of the medium and can protect the metal surface from corrosion, Fig. 1. shows the FT-IR test and the strongest frequencies which explain the strongest compounds that can help the Olive stone powder to be a powerful inhibitor.

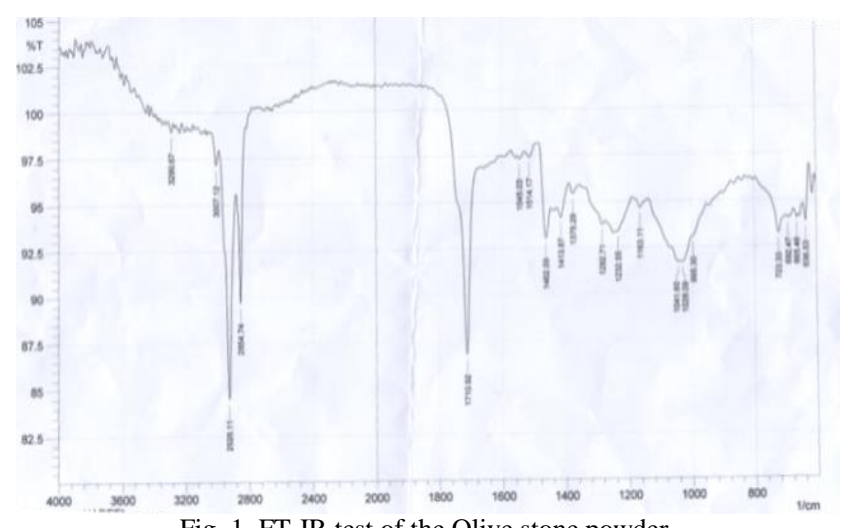

Fig. 1. FT-IR test of the Olive stone powder.

Briefly, Table II clarifies the major functional group in the Olive stone powder which obtained from the FT-IR test that makes the Olive stone a success inhibitor in various mediums.

TABLE II: THE MAJOR IMPORTANT FREQUENCIES IN THE OLIVE STONE POWDER FTIR TEST.

\begin{tabular}{ccc}
\hline \hline $\begin{array}{c}\text { Major functional } \\
\text { group }\end{array}$ & $\begin{array}{c}\text { Stretching frequency } \\
\mathrm{cm}-1\end{array}$ & Absorption Intensity \\
\hline $\mathrm{C}-\mathrm{H}$ & 2854.7 & strong \\
$\mathrm{C}-\mathrm{H}$ & 2926.1 & strong \\
$\mathrm{C}=\mathrm{O}$ & 1710.9 & strong \\
\hline \hline
\end{tabular}

\section{Electrochemical Measurements}

The electrochemical measurements were prepared for the same environments, with cylindrical specimens of $4.8 \mathrm{~cm}^{2}$ surface area. The potentiostat instrument used for electrochemical corrosion measurement named (Tafel test) is of a Gamry Series G300 Potentiostat this device built in a Computer. The tests can be done in to two types connection, one of three electrodes connections (working electrode + working sense, reference electrode and counter electrode), and with two electrode connections (working electrode+ working sense and counter electrode + reference). The reference electrode was saturated Calomel reference electrode and a graphite rod was used as a counter electrode. All experiments were applied at room temperature, and using Gamry workframe software program for recording experiment data. Recorded Data can be saved were analyzed with Gamry Echem Analyst software. Fig. 2 is clarifying the experiment setup for all Tafel tests.

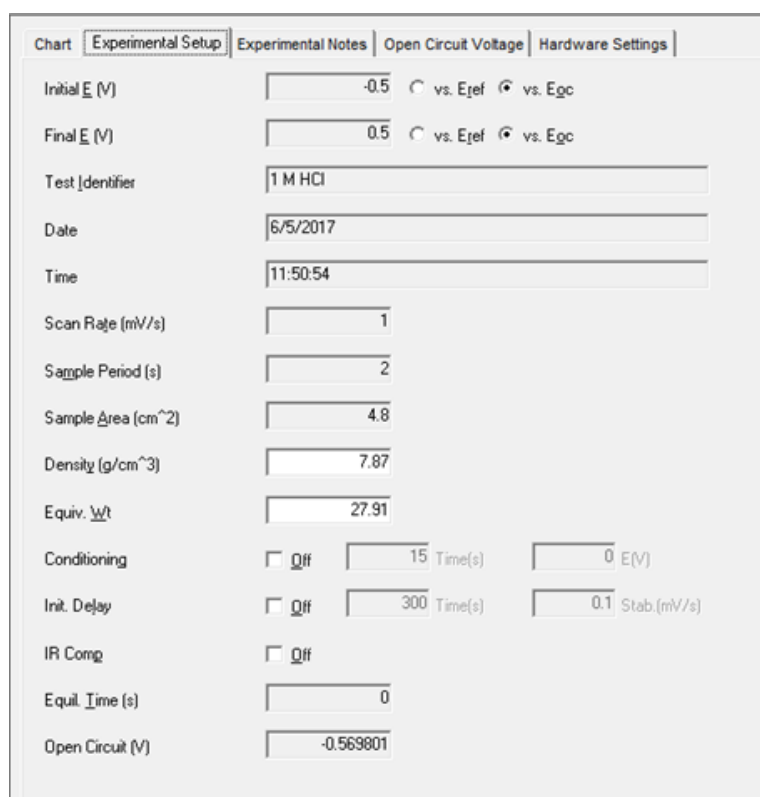

Fig. 2. The electrochemical experiments setup.

\section{RESULTS AND DISCUSSIONS}

Using Gamry company instrument Series device G300 Potentiostat built in a Computer for electrochemical Tafel tests with three electrodes connection .The Electrochemical kinetic of a corroding metal can be categorized by determining at least three polarization parameters, like current density (icorr), corrosion potential (Ecorr), and Tafel slopes ( $\beta \mathrm{A}$ and/or $\beta C$ ). Then the corrosion behavior can be clarified by a polarization curve ( $\mathrm{E}$ vs. $\log \mathrm{i})$. This is an accelerated electrochemical process for measuring the corrosion rate. Fig. 3 shows the Tafel scan curves for $0.5 \mathrm{M}$ of $\mathrm{HCl}$ at $40{ }^{\circ} \mathrm{C}$ temperature with and without Olive stone powder inhibitor, the polarization curve of the anodic and cathodic reactions when adding the Olive stone powder to the $0.5 \mathrm{M}$ of $\mathrm{HCl}$ shows disinclination as compared with the polarization curve of anodic and cathodic reactions of $0.5 \mathrm{M}$ $\mathrm{HCl}$ before adding the Olive stone powder, this phenomena cause to reduce corrosion rate by $66.3 \%$, this is due to the action of Olive stone powder that reduce the activity of the $\mathrm{HCl}$ medium.

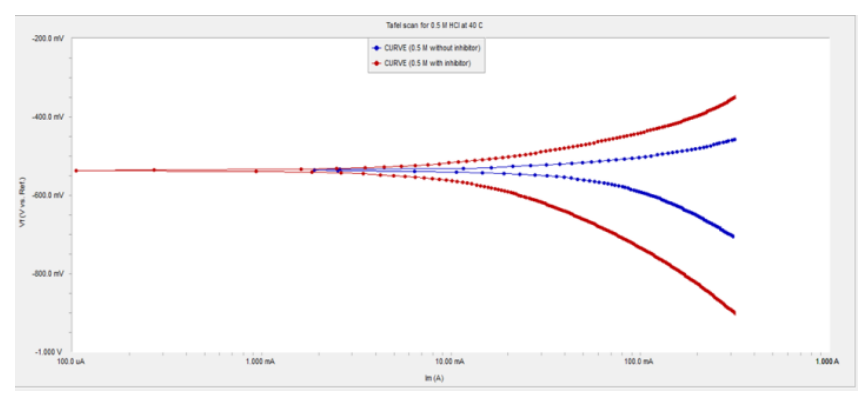

Fig. 3. Tafel curves for electrochemical experiments of $0.5 \mathrm{M} \mathrm{HCl}$ with and without Olive stone powder at $40^{\circ} \mathrm{C}$.

Fig.4 shows the Tafel scan curves for $1 \mathrm{M}$ of $\mathrm{HCl}$ with and without Olive stone powder inhibitor at $40{ }^{\circ} \mathrm{C}$, the polarization curve of the anodic and cathodic reactions when adding the Olive stone powder to the $1 \mathrm{M}$ of $\mathrm{HCl}$ shows disinclination as compared with the polarization curve of anodic and cathodic reactions of $1 \mathrm{M} \mathrm{HCl}$, this phenomenon 
causes to reduce corrosion rate by $80.3 \%$, this is due to the action of Olive stone powder that reduce the activity of the $\mathrm{HCl}$ medium.

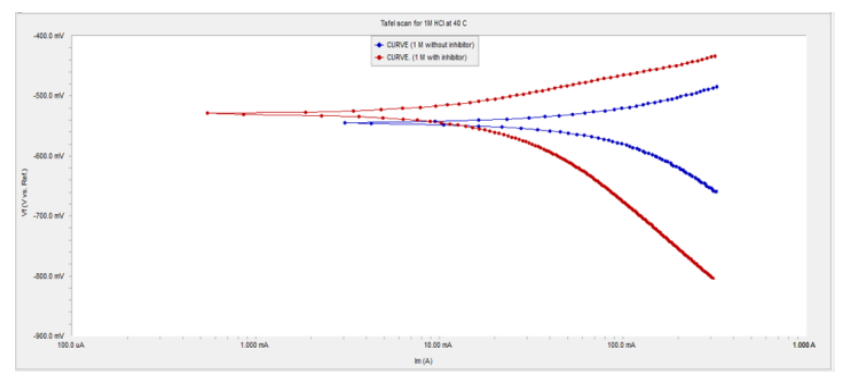

Fig. 4. Tafel curves for electrochemical experiments of $1 \mathrm{M} \mathrm{HCl}$ with and without Olive stone powder $40^{\circ} \mathrm{C}$.

Fig. 5 shows the Tafel scan curves for $1.5 \mathrm{M}$ of $\mathrm{HCl}$ with and without Olive stone powder inhibitor at $40{ }^{\circ} \mathrm{C}$, the polarization curve of the anodic and cathodic reactions when adding the Olive stone powder to the $1.5 \mathrm{M}$ of $\mathrm{HCl}$ shows disinclination as compared with the polarization curve of anodic and cathodic reactions of $1.5 \mathrm{M} \mathrm{HCl}$, this phenomenon causes to reduce corrosion rate by $85.2 \%$, this is due to the action of Olive stone powder that reduce the activity of the $\mathrm{HCl}$ medium.

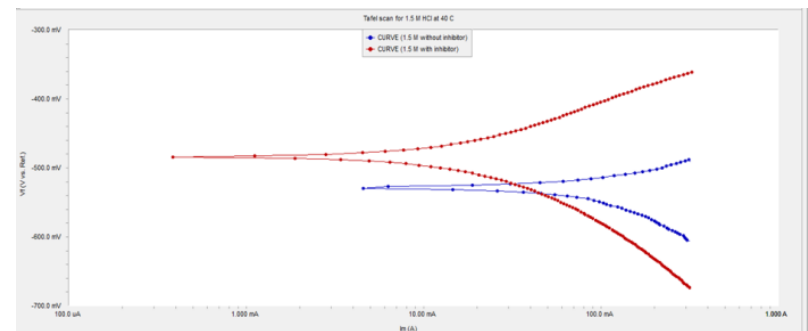

Fig. 5. Tafel curves for electrochemical experiments of $1.5 \mathrm{M} \mathrm{HCl}$ with and without Olive stone powder at $40^{\circ} \mathrm{C}$.

Table III shows the values of Tafel curves parameter of the $\mathrm{HCl}$ mediums that are used with and without Olive stone powder addition. These parameters are calculated by the Gamry Echem Analyst software. This table show that the corrosion rate in mpy without adding Olive stone powder is much higher than adding the Olive stone powder to the $\mathrm{HCl}$ acid and Tafel parameter $\left(\mathrm{E}_{\mathrm{corr}}, \beta_{\mathrm{C}}, \beta_{\mathrm{A}}\right)$ are about to be close each other.

TABLE III: PARAMETERS VALUE OF TAFEL TEST FOR 0.5, 1, $1.5 \mathrm{M}$ OF HCL WITH AND WITHOUT OLIVE STONE POWDER AT $40^{\circ} \mathrm{C}$

\begin{tabular}{cccccc}
\hline \hline $\begin{array}{c}\mathrm{HCl} \text { solution } \\
\text { medium }\end{array}$ & $\beta_{\mathrm{A}}, 10^{-3}$ & $\beta \mathrm{c}, 10^{-3}$ & $\begin{array}{c}\mathrm{I}_{\text {corr }} \\
\mathrm{mA}\end{array}$ & $\begin{array}{c}\mathrm{E}_{\text {corr }} \\
\mathrm{mV}\end{array}$ & $\begin{array}{c}\text { Corrosion } \\
\text { rate, } \mathrm{mpy}\end{array}$ \\
\hline $0.5 \mathrm{M}$ & 64 & 118 & 37.2 & 535 & 3542 \\
$1 \mathrm{M}$ & 107.3 & 267.3 & 112 & 545 & 10620 \\
$1.5 \mathrm{M}$ & 84.4 & 237.3 & 148 & 535 & 14060 \\
$0.5 \mathrm{M}+$ & 104.1 & 209.8 & 12.50 & 537 & 1191 \\
$\begin{array}{c}\text { Inhibitor } \\
1 \mathrm{M}+\end{array}$ & 101.6 & 213.6 & 22 & 530 & 2087 \\
$\begin{array}{c}\text { Inhibitor } \\
1.5 \mathrm{M}+\end{array}$ & 117.4 & 140 & 21.8 & 484 & 2071 \\
Inhibitor & & & & & \\
\hline \hline
\end{tabular}

Fig. 6 shows the Tafel scan curves for $0.5 \mathrm{M}$ of $\mathrm{HCl}$ with and without Olive stone powder inhibitor at $55{ }^{\circ} \mathrm{C}$, the polarization curve of the anodic and cathodic reactions when adding the Olive stone powder to the $0.5 \mathrm{M}$ of $\mathrm{HCl}$ shows fairly disinclination as compared with the polarization curve of anodic and cathodic reactions of $0.5 \mathrm{M} \mathrm{HCl}$, this phenomenon causes to reduce corrosion rate by $49.6 \%$, this is due to the action of Olive stone powder that reduce the activity of the $\mathrm{HCl}$ medium.

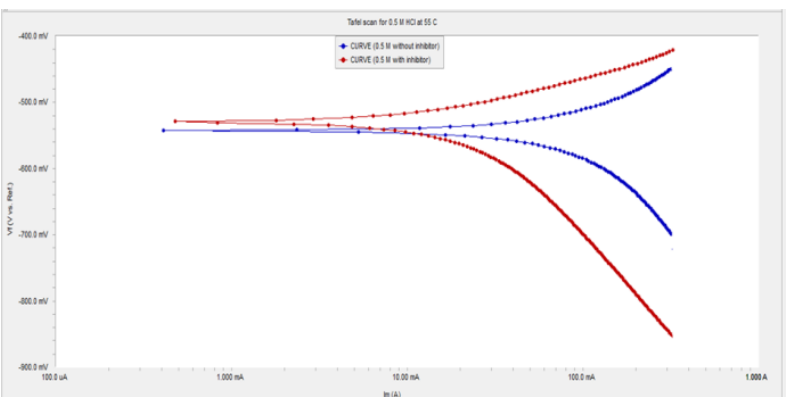

Fig. 6. Tafel curves for electrochemical experiments of $0.5 \mathrm{M} \mathrm{HCl}$ with and without Olive stone powder at $55^{\circ} \mathrm{C}$.

Fig.7 shows the Tafel scan curves for $1 \mathrm{M}$ of $\mathrm{HCl}$ with and without Olive stone powder inhibitor at $55{ }^{\circ} \mathrm{C}$, the polarization curve of the anodic and cathodic reactions when adding the Olive stone powder to the $1 \mathrm{M}$ of $\mathrm{HCl}$ shows medium disinclination as compared with the polarization curve of anodic and cathodic reactions of $1 \mathrm{M} \mathrm{HCl}$, this phenomenon causes to reduce corrosion rate by $93.1 \%$, this is due to the action of Olive stone powder that reduce the activity of the $\mathrm{HCl}$ medium.

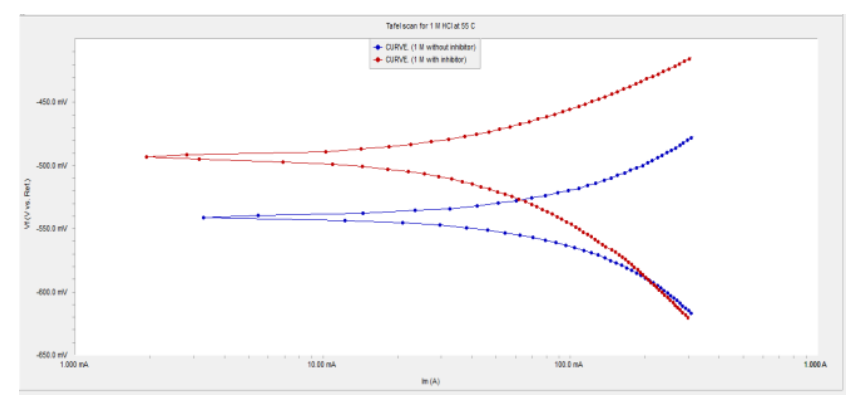

Fig. 7. Tafel curves for electrochemical experiments of $1 \mathrm{M} \mathrm{HCl}$ with and without Olive stone powder at $55^{\circ} \mathrm{C}$.

Fig. 8 shows the Tafel scan curves for $1.5 \mathrm{M}$ of $\mathrm{HCl}$ with and without Olive stone powder inhibitor at $55{ }^{\circ} \mathrm{C}$, the polarization curve of the anodic and cathodic reactions when adding the Olive stone powder to the $1.5 \mathrm{M}$ of $\mathrm{HCl}$ shows maximum disinclination as compared with the polarization curve of anodic and cathodic reactions of $1.5 \mathrm{M} \mathrm{HCl}$, this phenomena cause to reduce corrosion rate by $93.8 \%$, this is due to the action of Olive stone powder that reduce the activity of the $\mathrm{HCl}$ medium and hence the corrosion rate will be eliminated because of the inhibiter addition.

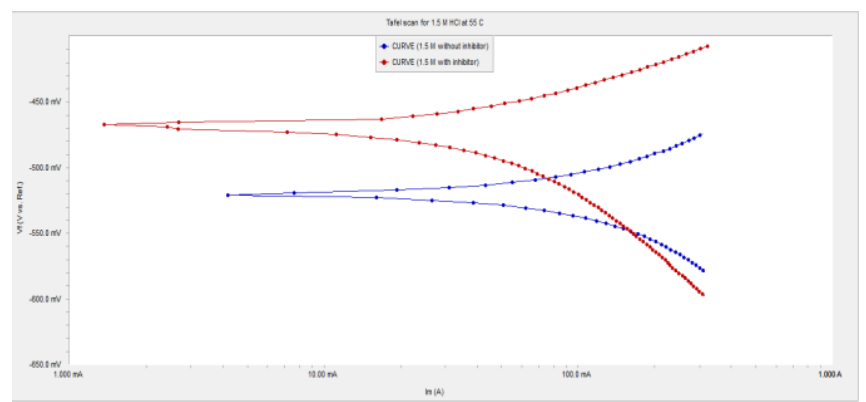

Fig. 8. Tafel curves for electrochemical experiments of $1.5 \mathrm{M} \mathrm{HCl}$ with and without Olive stone powder at $55^{\circ} \mathrm{C}$. 
Table IV shows the values of Tafel curves parameter of the $\mathrm{HCl}$ mediums that are used with and without Olive stone powder addition at $55^{\circ} \mathrm{C}$. These parameters are calculated by the Gamry Echem Analyst software. This table show that the corrosion rate in mpy without adding Olive stone powder is much higher than adding the Olive stone powder to the $\mathrm{HCl}$ acid and Tafel parameter $\left(\mathrm{E}_{\mathrm{corr}}, \beta_{\mathrm{C}}, \beta_{\mathrm{A}}\right)$ are about to be close each other.

TABLE IV: PARAMETERS VALUE OF TAFEL TEST FOR $0.5,1,1.5 \mathrm{M}$ OF HCL WITH AND WITHOUT OLIVE STONE POWDER AT $55^{\circ} \mathrm{C}$

\begin{tabular}{|c|c|c|c|c|c|}
\hline $\begin{array}{l}\mathrm{HCl} \text { solution } \\
\text { medium }\end{array}$ & $\beta_{\mathrm{A}}, 10^{-3}$ & $\beta \mathrm{c}, 10^{-3}$ & $\begin{array}{l}\mathrm{I}_{\text {corr }} \\
\mathrm{mA}\end{array}$ & $\begin{array}{l}\mathrm{E}_{\text {corr }} \\
\mathrm{mV}\end{array}$ & $\begin{array}{l}\text { Corrosion } \\
\text { rate, mpy }\end{array}$ \\
\hline $0.5 \mathrm{M}$ & 70.3 & 94.1 & 43 & 543 & 4096 \\
\hline $1 \mathrm{M}$ & 382.5 & 2.30 & 645 & 541 & 61390 \\
\hline $1.5 \mathrm{M}$ & 327.6 & 1.41 & 704 & 520 & 66980 \\
\hline $\begin{array}{c}0.5 \mathrm{M}+ \\
\text { Inhibitor }\end{array}$ & 96.9 & $\begin{array}{c}247 . \\
2\end{array}$ & 21.7 & 529 & 2062 \\
\hline $\begin{array}{c}1 \mathrm{M}+ \\
\text { Inhibitor }\end{array}$ & 85.4 & $\begin{array}{c}131 . \\
5\end{array}$ & 44.5 & 493 & 4234 \\
\hline $\begin{array}{l}1.5 \mathrm{M}+ \\
\text { Inhibitor }\end{array}$ & 76.2 & $\begin{array}{c}101 . \\
2\end{array}$ & 42.3 & 531 & 4105 \\
\hline
\end{tabular}

The efficiency of the Olive stone powder increase with increasing the concentration of $\mathrm{HCl}$ and temperature in this experiment study which observed in Fig. 9.

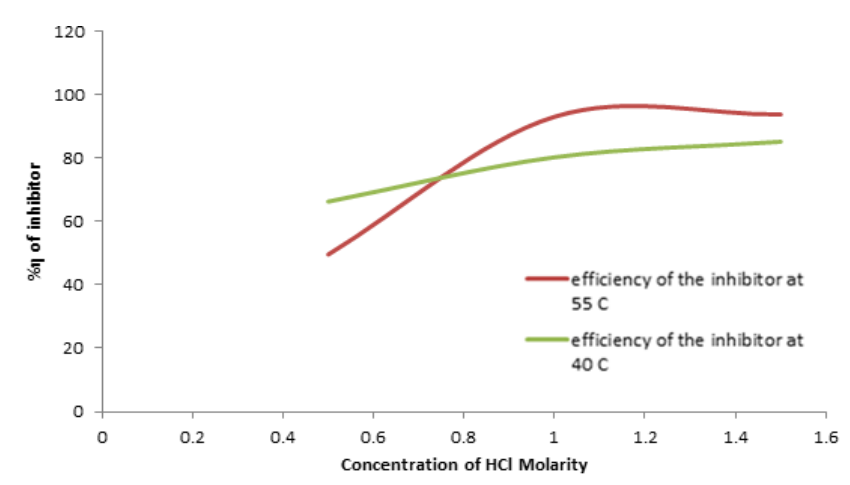

Fig. 9. The relationship between $\%$ efficiency of Olive stone powder in different concentrations of $\mathrm{HCl}$.

The efficiency percent of inhibitor can be calculated from the general efficiency equation,

$$
\% \eta=\frac{W_{i}-W_{e}}{W_{i}} \times 100
$$

Where: $\% \eta=$ percent inhibitor efficiency.

$\mathrm{W}_{\mathrm{i}}=$ Corrosion rate without inhibitor.

$\mathrm{W}_{\mathrm{e}}=$ Corrosion rate with inhibitor.

\section{CONCLUSION}

1. The Olive stone powder can be used as a natural corrosion inhibitor.

2. The inhibitor efficiency of the Olive stone powder increased with increasing the concentration of $\mathrm{HCl}$.

3. The Olive stone powder will be more efficient at high temperature environment.
4. The Olive stone powder is an organic material which consists of carbon and hydrogen hence may be combined to form carbonic acid one of the reasons that reduce the acidity of the medium.

5. The Olive stone powder may be adsorbed on the metal surface and hence form a barrier to protect the surface of metal from corrosion.

\section{ABBREVIATIONS}

A list of symbols which used in this research

$\begin{array}{cl}i_{\text {corr }} & \text { Corrosion current } \\ E_{\text {corr }} & \text { Potential corrosion } \\ \beta c & \text { Beta cathode, Tafel constant slope } \\ \beta_{A} & \text { Beta anode, Tafel constant slope } \\ \eta & \text { Inhibitor efficiency. }\end{array}$

\section{REFERENCES}

[1] Thompson, N. G., Yunovich, M., \& Dunmire, D. "Cost of corrosion and corrosion maintenance strategies," Corrosion Reviews., 25(3-4), 247-262, (2007).

[2] Buchweishaija, J. "Phytochemicals as green corrosion inhibitors in various corrosive media: a review." Tanzania Journal of Science, vol 35, no. 1, (2009).

[3] Sharma, S.K., Mudhoo, A. and Khamis, E. "Adsorption Studies, Modeling, and Use of Green Inhibitors in Corrosion Inhibition: An Overview of Recent Research," Green Corrosion Chemistry and Engineering: Opportunities and Challenges, pp.319-337, 2008.

[4] Patni, N., Agarwal, S. and Shah, P., "Greener approach towards corrosion inhibition," Chinese Journal of Engineering, 2013.

[5] Kabanda, M.M. and Ebenso, E.E., "Density functional theory and quantitative structure-activity relationship studies of some quinoxaline derivatives as potential corrosion inhibitors for copper in acidic medium," Int J Electrochem Sci, vol. 7, no. 9, pp.8713-8733, 2012.

[6] Kabanda, M.M., Murulana, L.C. and Ebenso, E.E., "Theoretical studies on phenazine and related compounds as corrosion inhibitors for mild steel in sulphuric acid medium," Int J Electrochem Sci, vol. 7, pp.7179-7205, 2012.

[7] Devarayan, K., Mayakrishnan, G. and Nagarajan, S. "Green Inhibitors for Corrosion of Metals: A Review", Chemical Science Review and Letters, Vol. 1, no. (1), pp. 1-8, 2012.

[8] Control of Environmental Variables in Water-Recirculating Systems, Corrosion, ASM Handbook, ASM International, 1987.

[9] Abd El-Maksoud, S.A., "Electrochemical studies on the effect of pyrazolo-containing compounds on the corrosion of carbon steel in 1 M sulphuric acid," Materials and Corrosion, vol. 54, no. 2, pp.106112, 2003.

[10] Bentiss F, Bouanis M, Mernari B, Traisnel M, Vezin H, Lagrenee M. "Understanding the adsorption of 4H-1,2,4-triazole derivatives on mild steel surface in molar hydrochloric acid.Appl". Surf. Sci.; vol. 253, pp. 3696 -704, 2007.

[11] Ebenso, EE. and Oguzie, EE. "Corrosion inhibition of mild steel in acidic media by some organic dyes,". Mater. Lett. Vol. 59, pp. 2163 $65,2005$.

[12] Omotoyinbo, J.A., Oloruntoba, D.T. and Olusegun, S. J. "Corrosion Inhibition of Pulverized Jatropha Curcas Leaves on Medium Carbon Steel in $0.5 \mathrm{M} \mathrm{H} 2 \mathrm{SO} 4$ and $\mathrm{NaCl}$ Environments", International Journal of Science and Technology, vol. 2, no. 7, pp. 510-514, 2013.

[13] Guillermo, R., Antonio, L., Rocio, R., Ana, J., Rafael, G. and Juan, F., "Olive stone an attractive source of bioactive and valuable compounds" Bioresource Technology, vol. 99, pp. 5261-5269, 2008.

[14] Cang, H., Fei, Z.H., Xiao, H.R., Huang, J.L. and Xu, Q., "Inhibition effect of reed leaves extract on steel in hydrochloric acid and sulphuric acid solutions," International Journal of Electrochemical Science, vol. 7, pp.8869-8882, 2012. 